\title{
Hepatotoxicidad por Fármacos
}

\author{
Francisco Tejada Cifuentes ${ }^{a}$
}

\begin{abstract}
aUnidad de Farmacia, Gerencia de Atención Primaria de Albacete (España).
\end{abstract}

Correspondencia: Francisco Tejada Cifuentes, Gerencia de Atención Primaria, C/ Dionisio Guardiola n 17 , 02001 - Albacete, España. Telf.: 967510825. Correo electrónico: ftejada@sescam. jccm.es

Recibido el 18 de enero de 2010.

Aceptado para su publicación el 30 de marzo de 2010.

\begin{abstract}
RESUMEN
El daño hepático causado por medicamentos, drogas de abuso o remedios medicamentosos (productos de herboristería, etc.) se está convirtiendo en un importante problema de salud pública que afecta a los pacientes, médicos, industria farmacéutica y agencias reguladoras. El daño hepático inducido por drogas es la causa más común de muerte por fallo hepático agudo y representa alrededor del $10 \%$ de casos de fallo hepático agudo a nivel mundial. La hepatotoxicidad por medicamentos es la principal reacción adversa implicada en el abandono del desarrollo de futuros medicamentos en la fase preclínica o clínica, denegación de registros por parte de las agencias reguladoras, y retirada del mercado o restricciones de uso después de ser registrado. La mayor parte de la información se obtiene de los datos referidos a las agencias reguladoras a través del sistema de notificación voluntaria (tarjeta amarilla) y por la información aparecida en las revistas médicas, pero esto probablemente es sólo la "punta del iceberg". El reconocimiento y diagnóstico de la hepatotoxicidad es a menudo difícil y largo en el tiempo, debido a la necesidad de excluir numerosas causas alternativas de daño hepático.
\end{abstract}

Palabras clave. Toxicidad de Medicamentos, Hepatopatías, Enfermedad Hepática Inducida por Drogas.

\section{ABSTRACT}

\section{Drug-induced hepatotoxicity}

Liver injury caused by medicines, recreational drugs, or non-standardized medical remedies (such as herbal products) is becoming a serious public health problem that affects patients, physicians, the pharmaceutical industry, and government regulators. Drug induced liver injury is the most common cause of death from acute liver failure and accounts for approximately $10 \%$ of cases of acute liver failure worldwide. Hepatotoxicity is the most frequent adverse drug event leading to abandonment of otherwise promising new drug candidates during the preclinical or clinical development stage, failure of drugs to obtain marketing authorisation approval by the regulatory agencies, and recall or restriction of prescription drugs after initial approval. The bulk of information is derived from the cases reported to the regulatory agencies by the spontaneous reporting system (yellow card) and those published in medical journals, but this is very probably only "the tip of the iceberg". The recognition and diagnosis of hepatotoxicity are often difficult and delayed due to the need to exclude more common competing causes of liver injury.

Key words. Drug Toxicity, Liver Diseases, Drug-Induced Liver Injury.

\section{INTRODUCCIÓN}

El hígado es un órgano que se afecta en numerosos procesos inflamatorios como infecciones víricas, toxicidad por fármacos y sus metabolitos, metabolopatías, procesos autoinmunes y distintos defectos genéticos. En los últimos años numerosas publicaciones sugieren que las reacciones adversas a fármacos son responsables de una mayor proporción de casos de lesión hepática de lo que inicialmente se pensaba, constituyendo un desafío para el médico de atención primaria, al que acuden con frecuencia pacientes tratados con varios fármacos que presentan, muchas veces en el curso de revisiones rutinarias, una alteración en la analítica hepática.

La hepatotoxicidad (HTX) se define como la lesión o daño hepático causado por la exposición a un medicamento u otros agentes no farmacológicos. 
Con el término reacción medicamentosa adversa se designa a la aparición de efectos deletéreos no intencionales que se producen con dosis farmacológicas utilizadas con fines profilácticos y terapéuticos ${ }^{1}$. Estas reacciones adversas que afectan al hígado son más difíciles de definir, por lo que dicho concepto ha sido establecido por reuniones de consenso e incluye, al menos, una de las siguientes alteraciones de los análisis bioquímicos hepáticos: 1) aumento de alanino aminotransferasa superior a dos veces el límite alto de la normalidad, 2) aumento de la concentración de bilirrubina directa sérica más de dos veces el límite alto de la normalidad, 3) aumento de aspartato aminotransferasa (AST), fosfatasa alcalina (FA) y la concentración total de bilirrubina, siempre que uno de ellos supere más de dos veces el límite alto de la normalidad ${ }^{2}$.

Los avances científicos y tecnológicos conllevan la mejoría del diagnóstico y tratamiento de muchas patologías, pero también están aumentando la incidencia de enfermedades yatrogénicas. Dado que el hígado es el principal órgano implicado en el metabolismo de nutrientes, fármacos y otros xenobióticos potencialmente tóxicos que deben atravesarlo antes de alcanzar el torrente sanguíneo y otros tejidos, lo hace particularmente susceptible a los fenómenos de toxicidad química. Es más, el número de sustancias ajenas al organismo con actividad biológica capaces de inducir enfermedad hepática es muy amplio, habiendo sido incriminados en la actualidad más de 1.100 fármacos en episodios de hepatotoxicidad, excluyendo drogas de abuso y remedios de herboristería ${ }^{3}$. Aunque las reacciones adversas hepáticas (RAH) se consideren relativamente raras en el conjunto de las reacciones adversas $(4-10 \%)$, tienen una especial trascendencia clínica debido a su potencial gravedad (hasta un $5 \%$ de mortalidad según las series) ${ }^{4}$. La hepatotoxicidad representa un problema sanitario de primer orden en aumento en las últimas décadas, dado que es una de las principales causas de muerte secundaria a medicamentos y supone la principal causa de retirada, suspensión de comercialización y restricción de las indicaciones de productos farmacológicos del mercado farmacéutico en Europa y en Estados Unidos ${ }^{5}$. Un ejemplo reciente de la importancia de las reacciones adversas hepáticas es el caso de la troglitazona, nuevo antidiabético oral que fue retirado del mercado a los tres años de su comercialización debido a casos de lesión hepática severa con resultado de transplante hepático e incluso muerte en algunos pacientes. Otros ejemplos de fármacos retirados recientemente del mercado por su potencial hepatotóxico son ebrotidina, tolcapona, nefazodona, tetrabamato, nimesulida, trovafloxacino y lumiracoxib.

\section{EPIDEMIOLOGÍA}

A pesar de que la información epidemiológica sobre el efecto tóxico de los fármacos en el hígado es escasa y fragmentaria, se sabe que la incidencia de HTX está aumentando de forma paralela a la introducción de nuevos agentes en el mercado, al aumento de la esperanza de vida, la polimedicación y al uso cada vez más extendido de productos herbales. El desconocimiento de la incidencia real de esta patología es debido a varias causas ${ }^{6}$. En primer lugar, la mayoría de los datos disponibles hoy día son de naturaleza retrospectiva y derivan de las observaciones de casos aislados o de series publicadas en la literatura, de la comunicación espontánea de incidencias a las agencias estatales de farmacovigilancia y de alguna información adicional obtenida de programas de vigilancia postcomercialización o de monitorización de poblaciones específicas. En segundo lugar, existe una infranotificación de casos por parte del personal sanitario en probable relación con el bajo índice de sospecha por parte del personal facultativo; y finalmente hay que tener en cuenta que, al no disponer de marcadores específicos de hepatotoxicidad, obtener un diagnóstico etiológico de certeza puede llegar a ser sumamente difícil. Todo lo expuesto explica que la notificación de casos de HTX no supere en la práctica el $10 \%$ de las que realmente acontecen. Un estudio prospectivo poblacional de incidencia de HTX publicado en los últimos años, realizado en una región francesa, analiza casos de daño hepático secundario a fármacos durante un periodo de tres años ${ }^{7}$. Recoge una tasa de incidencia anual de 13,9 casos $\pm 2,4$ DE de HTX por cien mil habitantes, con una incidencia estandarizada global de 80 casos por millón de habitantes y año, de los cuales el $12 \%$ precisaron hospitalización y el $6 \%$ fallecieron. Los autores del estudio extrapolaron dichos resultados al resto de la población francesa, calculando una incidencia de 8.000 casos de hepatotoxicidad nuevos al año, entre los cuales habría 500 fallecimientos por dicho motivo. Es importante señalar que estos resultados suponían un número de casos de HTX 16 veces mayor de los que se notifican a las autoridades sanitarias francesas, corroborando la existencia del problema de la infranotificación previamente expuesto.

En España, Ibáñez y cols. realizaron un estudio prospectivo en Cataluña, cuyo resultado obtuvo una incidencia de 7,4 casos de enfermedad hepática aguda severa secundaria a fármacos por millón de habitantes y año, con una mortalidad de 0,8 por millón y año ${ }^{8}$. A diferencia de este estudio, la incidencia calculada por otro grupo en Málaga fue mayor, resultando una incidencia anual cruda del 34,2 $\pm 10,7$ casos por millón y una incidencia de enfermedad hepática seria del 16,6 \pm 6,7 casos por millón de habitantes y año. La razón por la que dicha incidencia sigue siendo menor que la hallada en Francia probablemente responde a que en el estudio local sólo se incluyeron los pacientes del centro hospitalario, sin contar los casos estudiados y seguidos en 
atención primaria y los pacientes pediátricos. Por último, un estudio de casos y controles poblacional retrospectivo, realizado utilizando una base de datos británica, estimó una incidencia de enfermedad hepática seria idiopática, posiblemente relacionada con fármacos, de 2,4 casos por 100.000 habitantes y año $0^{9}$. Se calcula que la HTX supone entre $1 / 600$ a $1 / 3.500$ de todos los ingresos hospitalarios y se estima que los fármacos son responsables del 2-5\% de los casos de ictericia que ingresan en un hospital, de aproximadamente un $10 \%$ de los casos de hepatitis aguda y de un $7-20 \%$ de los casos de insuficiencia hepática fulminante ${ }^{10}$.

En España la hepatitis tóxica constituye el 14\% de los casos de lesión hepática que ingresan en un hospital (valorada como elevación de transaminasas por encima de $400 \mathrm{UI} / \mathrm{dl}$ ). Otro dato importante es que los fármacos han alcanzado el primer puesto como causa de fallo hepático fulminante (FHF) tanto en Estados Unidos como en Europa ${ }^{12}$. Un estudio prospectivo multicéntrico del grupo cooperativo Acute Liver Failure Study Group (ALFSG), que valora los ingresos consecutivos de pacientes con fracaso hepático agudo en 17 hospitales de Estados Unidos, señala los medicamentos (incluyendo los casos de intoxicación por paracetamol: $39 \%$ ) como la causa más frecuente de fallo hepático agudo, superando incluso a las producidas por los virus de hepatitis $A$ y $B^{11}$. El porcentaje de casos de fallo hepático fulminante secundario a hepatotoxicidad de tipo idiosincrásico varía de un $7 \%$ a un $16 \%$ según estudios realizados en distintos países ${ }^{13}$. No obstante, todavía una proporción sustancial de casos de insuficiencia hepática aguda grave permanecen sin clasificar tras una evaluación exhaustiva. La detección de aductos paracetamol-proteína (marcador subrogado de HTX) en un $19 \%$ de este tipo de pacientes ha arrojado nuevas evidencias sobre la responsabilidad de los fármacos en, al menos, una parte de los casos de fallo hepático idiopático. Aunque es importante tener presente que cualquier fármaco o sustancia ajena al organismo puede ser susceptible de provocar lesión hepática, existe una gran variabilidad en el potencial hepatotóxico de los distintos medicamentos. Dicho potencial lesivo o frecuencia con la que un agente medicinal induce toxicidad hepática es también desconocido en la práctica, ya que, aunque para ciertos medicamentos pueda calcularse con relativa precisión el número de casos de daño hepático (numerador), es imposible determinar el total de sujetos expuestos (denominador). La mayoría de las estimaciones sitúan la prevalencia de las reacciones adversas hepáticas idiosincrásicas entre 1/10000 a 1/100000 exposiciones para la mayoría de los fármacos. En la actualidad, los fármacos comercializados que presentan mayor prevalencia de hepatotoxicidad (alrededor de un $1 \%$ ) son la isoniazida, la clorpromacina y la tacrina ${ }^{14}$.
Además de lo expuesto, la frecuencia de los fármacos imputados en eventos de toxicidad hepática cambia en el tiempo y de unos países a otros. En los años 60 la causa más frecuente de ictericia producida por fármacos era la clorpromacina, siendo sustituida por el halotano en la década de los 70$80^{10}$. Estos fármacos han sido sustituidos hoy día por otros con menor potencial hepatotóxico, pero mayor número de prescripciones, por lo que en la actualidad los grupos farmacológicos más frecuentemente incriminados en la aparición de reacciones hepatotóxicas idiosincrásicas son los anti-infecciosos, incluyendo los antituberculosos, los fármacos del sistema nervioso central y los músculoesqueléti$\cos ^{8,11}$. En cuanto a la diferencia geográfica, el paracetamol es el fármaco que con mayor frecuencia es imputado como causa de HTX en el Reino Unido y en Estados Unidos ${ }^{11,12}$. En cambio, en nuestro ámbito el fármaco que de forma independiente produce mayor número de casos de HTX es el antibiótico amoxicilina-ácido clavulánico (14\% de todos los casos incluidos en un registro de hepatotoxicidad ${ }^{15}$. Por último, otras sustancias que están ganando importancia en las reacciones hepatotóxicas son las drogas de abuso como la cocaína, el éxtasis y los derivados anfetamínicos, los productos herbales y los excipientes de las formulaciones de los fármacos.

\section{ETIOPATOGENIA}

Existen dos tipos de hepatotoxicidad: intrínseca e idiosincrásica. La HTX intrínseca, o dosis dependiente, es predecible y reproducible y ocurre con una minoría de fármacos. Mientras algunas de estas hepatotoxinas actúan directamente sobre el hepatocito, otras lo hacen a través de un compuesto tóxico generado durante su metabolismo cuyo ejemplo más característico es el paracetamol. Otros ejemplos de hepatotoxicidad intrínseca son los producidos por el ácido acetilsalicílico, la intoxicación por setas (amanita phaloides) y las alteraciones hepáticas producidas por productos industriales como el tetracloruro de carbono. La HTX idiosincrásica, en cambio, ocurre de modo impredecible, no se relaciona con la dosis y no es reproducible en animales de experimentación. Esta última a su vez se divide en idiosincrasia metabólica e inmunoalérgica ${ }^{16}$.

El metabolismo de los fármacos en el hígado se produce fundamentalmente en dos fases (figura 1). Las reacciones de fase I consisten en reacciones de oxidación y reducción que modifican o crean nuevos grupos funcionales, así como reacciones de hidrólisis que rompen los enlaces ésteres y amidas y liberan también nuevos grupos funcionales. Estos cambios se siguen de un aumento de la hidrosolubilidad de los metabolitos, lo cual facilita su excreción biliar y urinaria. Las reacciones de fase II son 


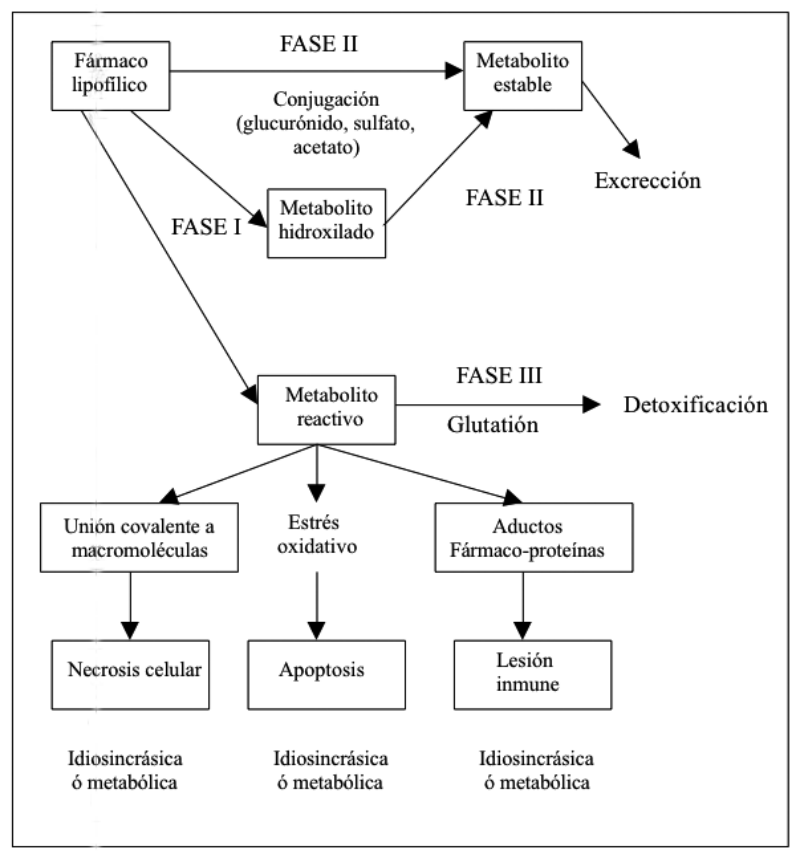

Figura 1. Metabolismo de fármacos en el hígado.

reacciones de conjugación en las que el fármaco o un metabolito derivado del mismo se acoplan con substratos endógenos como el ácido glucurónico, acético o sulfúrico, que nuevamente generan metabolitos más solubles en medios hídricos facilitando de esta forma su excreción. La mayoría de los mecanismos celulares implicados en la lesión hepática tóxica idiosincrásica siguen siendo desconocidos. La hipótesis más plausible es la generación de metabolitos reactivos durante las reacciones de biotransformación hepática de fase I controladas por el citocromo P-450 (CYP450), un conjunto de enzimas microsomales bajo control genético. La ausencia de un determinado CYP o la presencia de polimorfismo en uno o varios CYP determinaría bien la inactivación del compuesto original (tóxico) o bien la formación de metabolitos aberrantes (idiosincrasia metabólica) ${ }^{17}$. El resultado de éste proceso es la presencia intracelular de radicales libres o compuestos electrofílicos que depleccionan el glutation de las células, se unen covalentemente a proteínas, lípidos o ácidos nucléicos o inducen peroxidación lipídica. La lesión citotóxica culmina en la muerte celular por necrosis o apoptosis. La necrosis es consecuencia directa de la peroxidación de los lípidos de membrana, dando lugar a la rotura celular y a la salida de componentes citosólicos al espacio extracelular. La apoptosis en cambio se caracteriza por la condensación progresiva de la cromatina nuclear, descrita sobre todo en relación con la toxicidad por ácidos biliares y mediada por un mecanismo dependiente de Fas (proteína receptora de la familiar de receptores del factor de necrosis tumoral alfa). El exceso de ácidos biliares en el citosol hepático ocasiona una traslocación del Fas citosólico a la membrana, uniéndose a su ligando fisiológico (FasL), lo cual desencadena la cascada de caspasas que culmina en la apoptosis celular. Sin embargo, el efecto citotóxico también puede ser secundario al estrés oxidativo que se genera durante el metabolismo de las toxinas. En situación de estrés oxidativo se produce una depleción de ATP, la oxidación de grupos sulfhidrilo de las proteínas, trastornos en la hemostasis iónica y un aumento sostenido en la concentración intracelular de $\mathrm{Ca}^{++}$. Todo esto conduce en última instancia a la pérdida de la integridad celular ${ }^{18}$. En una minoría de casos el metabolito reactivo presumiblemente forma aductos con proteínas o con el propio enzima microsomal que lo ha generado, comportándose como un neoantíageno. Estos neoantígenos, formados a nivel del citosol, migran hacia la membrana celular bien vía vesicular o uniéndose a moléculas HLA de membrana, desde donde estimulan la respuesta inmune celular y humoral dirigida contra las células hepáticas originando así las reacciones idiosincrásicas inmunoalérgicas o por hipersensibilidad ${ }^{18}$. En raras ocasiones la hepatotoxicidad idiosincrásica sobreviene por un fallo genéticamente condicionado en los sistemas enzimáticos de detoxificación (reacciones de fase II) encargados de neutralizar los metabolitos reactivos, los cuales pueden dar lugar a determinados síndromes como la colestasis, al inhibir transportadores específicos de la bilis, o a la esteatosis microvesicular y esteatohepatitis al alterar la $\beta$-oxidación mitocondrial. En resumen, los mecanismos de hepatotoxicidad incluyen la necrosis celular por peroxidación lipídica, la apoptosis, el estrés oxidativo, la formación de metabolitos reactivos que pueden llevar a reacciones inmunológicas o autoinmunes, y las alteraciones de la función mitocondrial (figura 2).

\section{FACTORES DE RIESGO}

La susceptibilidad individual al daño hepático farmacológico depende de factores tanto genéticos como adquiridos. Dichos factores actuarían presumiblemente mediante la inducción o inhibición del CYP, o mediante la interferencia con los sistemas enzimáticos detoxificadores. Los factores de riesgo comúnmente relacionados con las reacciones adversas hepáticas son los factores genéticos, la edad, el sexo, los factores metabólicos y hormonales, el consumo de alcohol, el uso concomitante de otros medicamentos y la presencia de determinadas enfermedades subyacentes.

Factores genéticos. La variabilidad genética es posiblemente el factor de riesgo más importante en hepatotoxicidad, ya que el polimorfismo genético tiene una fuerte influencia en el metabolismo de los medicamentos y sustancias ajenas al organismo ${ }^{19}$. Los factores genéticos determinan no sólo la actividad de las vías de metabolización de fármacos y otras sustancias xenobióticas, sino también la 


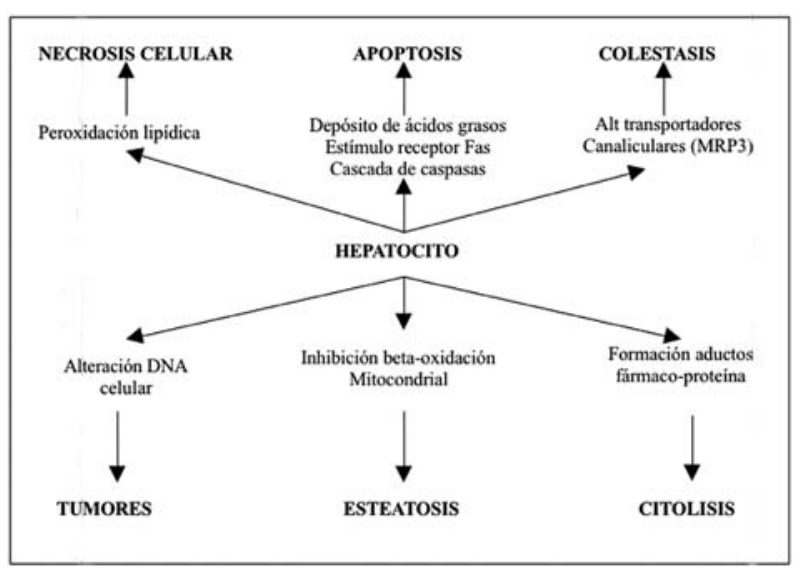

Figura 2. Esquema de los principales mecanismos patogénicos implicados en el desarrollo de alteraciones hepatotóxicas.

efectividad de los factores protectores del huésped como los antioxidantes y la regulación de la respuesta inmunológica. Los ejemplos documentados de HTX relacionados con una predisposición familiar son escasos e involucran al halotano y la fenitoina ${ }^{20}$. Además, las alteraciones mitocondriales hereditarias representan un factor de riesgo para las $\mathrm{RAH}$ debidas a ácido valproico ${ }^{21}$. La existencia de polimorfismos genéticos del complejo enzimático citocromo P-450 y de otras enzimas hepáticas provoca una variabilidad individual en el metabolismo de los medicamentos que puede favorecer o producir reacciones de hepatotoxicidad. El ejemplo más característico es la asociación entre el déficit de

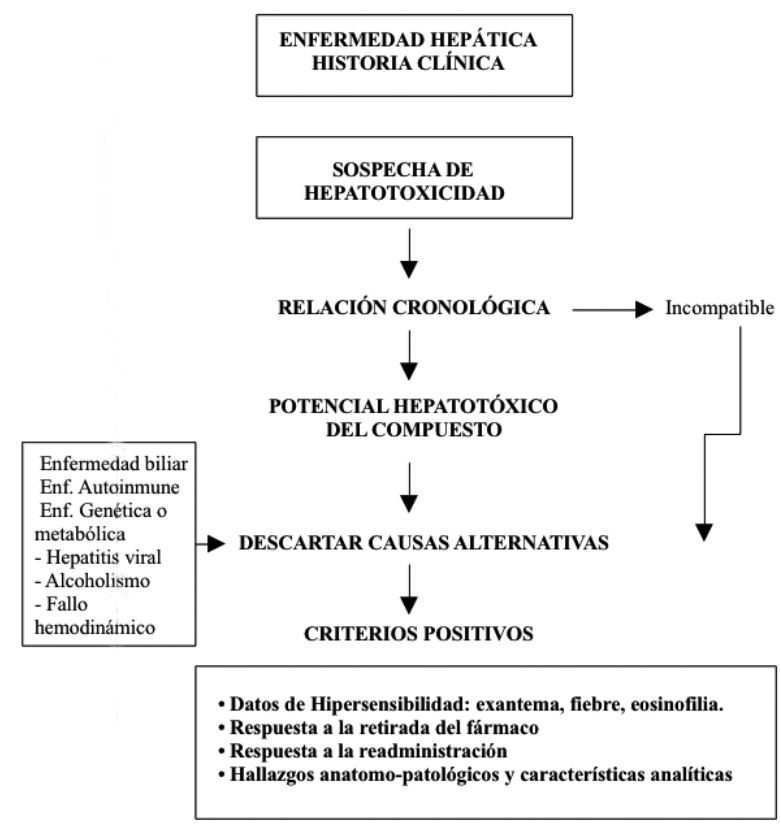

Figura 3. Algoritmo diagnóstico en la valoración "paso a paso" de los casos de enfermedad hepática con sospecha de hepatotoxicidad (Andrade et al).
CYP2D6 y la HTX secundaria a perhexilina. También se ha observado una asociación entre el déficit de CYP2C19 con la HTX secundaria al tetrabamato, combinación de febarbamato, difebarbamato y fenobarbital, y la producida por la troglitazona o el polimorfismo del CYP2E1 y la HTX por fármacos antituberculosos. La disminución de la capacidad de acetilación debido a la reducción del $\mathrm{N}$-acetil transferasa tipo 2 (NAT2) o acetiladores lentos se ha incriminado en la toxicidad por sulfonamidas, hidralacina o isoniazida. Por último, se ha relacionado la reducción de la capacidad de glucuronización en pacientes con síndrome de Gilbert y la toxicidad por irinotecan 22 . Actualmente existe controversia respecto a si variaciones genéticas en moléculas del complejo mayor de histocompatibilidad (HLA II) determinarían cierta predisposición a las RAH debido al papel que desempeñan en la respuesta inmunológica. Sin embargo, sí se ha observado una influencia genética del HLA II en la expresión bioquímica de la lesión hepática colestásica o mixta (relación directa con los alelos HLA-DRB1*15 y HLA DQB1*06 e inversa con la expresión de los alelos DRB1*07 y DQB1*02), lo cual explicaría la posibilidad de producir distintos tipos de lesión por un mismo fármaco. Además, dichos hallazgos sugieren que una parte importante de casos de HTX de tipo colestásico/mixto podría tener un origen inmunoalérgico determinado genéticamente. Finalmente, parece existir una mayor predisposición de RAH en los individuos con antecedentes familiares de hepatotoxicidad inmunoalérgica y en pacientes con antecedentes personales de atopia, aunque dichas afirmaciones están pendientes de comprobación.

Edad. La afirmación sobre el aumento de la incidencia de HTX con la edad está siendo cuestionada en los últimos años. Esta predisposición parece más evidente para fármacos como la isoniazida, el halotano o la nitrofurantoína y parece ser debido a un conjunto de eventos como una capacidad metabólica reducida, cambios en el flujo sanguíneo hepático y en la respuesta inmune tisular, la disminución del aclaramiento renal y la polimedicación a la que están expuestos. Sin embargo, la toxicidad hepática inducida por aspirina (síndrome de Reye) y el ácido valpróico son más frecuentes en la edad infanti ${ }^{23}$. Por otro lado, la edad no solo influye en la incidencia de reacciones adversas sino también en el pronóstico de las mismas, como ocurre en el caso de la intoxicación por paracetamol en la que la edad mayor de 40 años se ha identificado como factor de riesgo independiente para el desarrollo de fallo hepático fulminante y mortalidad.

Sexo. Clásicamente se ha atribuido un mayor riesgo de hepatotoxicidad en el sexo femenino, fundamentalmente en algunas variedades como la hepa- 
titis crónica o la toxicidad producida por determinados fármacos como el halotano, la alfa-metildopa, la tetraciclina, la nitrofurantoína y el diclofenaco. En cambio, la hepatotoxicidad por azatioprina parece ser más frecuente en el sexo masculino ${ }^{11}$. Sin embargo, una publicación reciente no demuestra diferencias significativas en la incidencia de hepatotoxicidad entre ambos sexos, exceptuando un predominio del sexo masculino en edades avanzadas y una mayor frecuencia del sexo femenino en pacientes con fallo hepático fulminante ${ }^{24}$.

Factores metabólicos y hormonales. Algunos factores metabólicos y hormonales como la obesidad, la desnutrición, la gestación y el hipertiroidismo incrementan el riesgo de toxicidad hepática por algunos fármacos ${ }^{2}$. Ejemplo de lo expuesto es el aumento del riesgo de HTX secundaria a halotano y metotrexato en pacientes obesos y/o con otros factores relacionados con la patogenia de la esteatohepatitis no alcohólica. En cambio, la malnutrición aumenta el riesgo de intoxicación por paracetamol en probable relación con la depleción de glutatión.

Alcohol. El consumo de alcohol incrementa el potencial hepatotóxico de medicamentos como el metrotexato, la isoniazida, el halotano, la cocaína y el paracetamol, El mecanismo es complejo y podría combinar la inducción de la isoforma CYP2E1, involucrada en el metabolismo de estas sustancias, el agotamiento intracelular de glutatión (resultado de la inhibición directa de su síntesis) y la malnutrición que suele acompañar al alcoholismo crónico.

Fármacos. Las interacciones entre fármacos pueden predisponer a la hepatotoxicidad, tanto por inducción de determinados isoenzimas del CYP, aumentando así la tasa de producción de metabolitos reactivos, como por inhibición del mismo. Este hecho está bien ilustrado por el mayor potencial hepatotóxico de la asociación de isoniazida con rifampicina que el de isoniazida sola. A la inversa, la inhibición microsomal del metabolismo estrogénico puede precipitar la aparición de colestasis. Es más, un estudio poblacional de casos-control demostró que la combinación de dos o más fármacos con potencial hepatotóxico aumentaba el riesgo de hepatotoxicidad por un factor de $6^{9}$.

Enfermedades asociadas. La presencia de determinadas enfermedades asociadas puede aumentar el riesgo de HTX por algunos medicamentos. Por ejemplo, los pacientes con infección por virus de la inmunodeficiencia humana (VIH) son más susceptibles al efecto tóxico del timetroprim-sulfametoxazol y las sulfonamidas. De igual modo, los pacientes con artritis reumatoide presentan un riesgo mayor de toxicidad hepática por ácido acetilsalicílico y están más predispuestos a la hepatotoxicidad con salazopirina que los aquejados de enfermedad in- flamatoria intestinal ${ }^{25}$. En general, la presencia de enfermedad hepática subyacente no parece ser un factor de riesgo de HTX, excepto para determinadas situaciones específicas como el metrotexato en la hepatopatía alcohólica, el tratamiento con antirretrovirales y antituberculosos en pacientes $\mathrm{VIH}$ coinfectados con los virus de hepatitis B y/o C, la administración de rifampicina como tratamiento del prurito en la cirrosis biliar primaria (resultados contradictorios en los últimos estudios realizados), el ibuprofeno en los pacientes con hepatitis crónica $\mathrm{C}$ o el mayor riesgo de desarrollar una enfermedad venooclusiva hepática secundaria al tratamiento mieloablativo en estos mismos pacientes ${ }^{26}$. Independientemente de las situaciones concretas descritas, el uso de fármacos con potencial hepatotóxico y la posibilidad de un mayor riesgo de HTX en pacientes con enfermedad hepática subyacente sigue siendo un tema controvertido. En cualquier caso, un episodio de hepatotoxicidad será de mayor gravedad en un paciente con enfermedad hepática de base, fundamentalmente cuando existe una disminución de la reserva funcional hepática.

Dosis. Algunos fármacos producen hepatotoxicidad dependiendo de la dosis administrada. En estos casos, cuanto mayor es la dosis mayor es el riesgo de sufrir hepatotoxicidad. El paracetamol es un ejemplo conocido de hepatotoxicidad en dosis supraterapéuticas o en pacientes susceptibles. En este tipo de fármacos el efecto hepatotóxico es dosis dependiente $y$, por tanto, se puede plantear una reducción de la dosis del fármaco sin suspenderlo totalmente. En la tabla 1 se indican algunos de estos fármacos en los que la aparición de una lesión hepática se ha asociado a la dosis administrada.

\section{TIPOS DE LESIÓN HEPATOTÓXICA}

Aunque el hepatocito es la célula diana habitual del efecto tóxico de los medicamentos sobre el hígado y la hepatitis aguda ictérica o anictérica la forma de presentación más frecuente de la hepatotoxicidad (90\% de los casos), cualquier célula parenquimatosa o no parenquimatosa del hígado puede resultar dañada de forma aislada o combinada, pudiendo simular cualquier tipo de enfermedad hepática conocida. Por lo tanto, el tipo de lesión va a depender fundamentalmente de la célula hepática predominantemente afectada ${ }^{6}$ :

- La lesión de los hepatocitos puede producir hepatitis aguda o crónica, esteatosis, hepatitis colestásica, cirrosis, hepatitis granulomatosa o tumores.

- El daño de los colangiocitos desembocaría en la aparición de colangitis aguda o crónica, o más raramente colangitis esclerosante.

- La toxicidad sobre las células endoteliales podría 
ser causa de enfermedad venooclusiva hepática, peliosis hepática, síndrome de Budd-Chiari o incluso del desarrollo de un angiosarcoma.

- El ataque de las células estrelladas (células de Ito) puede causar fibrosis hepática.

\section{A. Lesión hepática aguda}

Las lesiones hepáticas agudas se definen como las alteraciones con evolución menor de 3 meses. A pesar de que la histología hepática es la herramienta más apropiada para la definición del patrón de lesión hepática, desde un punto de vista práctico y debido a que en muchas ocasiones no se dispone de esta información, el panel de expertos del Grupo Internacional de Consenso propuso no sólo una serie de definiciones con el fin de unificar el lenguaje de las reacciones adversas hepáticas sino también la clasificación del tipo de daño hepático sobre la base de criterios de laboratorio en ausencia de biopsia hepática como se describe a continuación²:

1. La lesión hepatocelular (citolítica, citotóxica) se caracteriza por un incremento aislado de ALT mayor del doble del límite superior de la normalidad o una relación entre ALT/FA expresada en múltiplos del límite superior de la normalidad mayor de 5. Los síntomas suelen ser inespecíficos, simulando generalmente una hepatitis viral aguda. Es la forma de HTX más frecuente y puede ser debida tanto a un mecanismo intrínseco (paracetamol), como idiosincrásico. La biopsia hepática suele mostrar grados variables de inflamación y necrosis de predominio centrolobulillar. En ocasiones puede derivar en una hepatitis aguda fulminante con una mortalidad sin transplante hepático cercana al $90 \%$. El factor pronóstico más importante para dicha evolución es la continuación del tratamiento tras el desarrollo de ictericia. La recuperación suele darse de 1-3 meses tras la suspensión del tratamiento.

2. La lesión colestásica se manifiesta por un incremento aislado de Fosfatasa Alcalina (FA) mayor del doble del límite superior de la normalidad o una relación entre Alanina aminotransferasa/ Fosfatasa Alcalina (ALT/FA) menor de 2. Dicho tipo de lesión puede ser de dos tipos:

- Colestasis blanda, pura o canalicular ("bland cholestasis"): este tipo de lesión es poco frecuente y se caracteriza por la aparición de ictericia y prurito con transaminasas normales o mínimamente alteradas en ausencia de signos de hipersensibilidad. La biopsia hepática muestra colestasis hepatocitaria y canalículos biliares dilatados con trombos de bilis, pero sin evidencia de necrosis o inflamación. El pronóstico de este tipo de lesión es bueno, siguiéndose de una recuperación completa y sin secuelas. Los medicamentos asociados a esta clase de alteraciones son los esteroides sexuales, la citarabina y la azatioprina.

- Hepatitis aguda colestásica o variedad hepatocanalicular: se manifiesta clínicamente por un cuadro de dolor a nivel del hipocondrio derecho que puede simular una patología de la vía biliar extrahepática, acompañándose frecuentemente de manifestaciones de hipersensibilidad. Los hallazgos histológicos incluyen inflamación portal y ductal, y necrosis hepatocitaria, junto a colestasis prominente de predominio centrolobulillar. La evolución natural de

\begin{tabular}{ll}
\hline Fármaco & Efecto dosis dependiente \\
\hline Amiodarona & Dosis acumulada: esteatohepatitis \\
Anticonceptivos orales & Dosis acumulada: asociación con adenomas hepáticos \\
Bromfenaco & Dosis acumulada: necrosis de hepatocitos \\
Ciclofosfamida & Dosis altas: necrosis de hepatocitos \\
Ciclosporina & Dosis altas: lesión colestásica \\
Cocaína & Dosis altas: necrosis isquémica \\
Metotrexato & Dosis altas o acumulada: necrosis de hepatocitos, fibrogenesis \\
Niacina & Dosis altas: necrosis isquémica \\
Paracetamol & Sobredosis: necrosis de hepatocitos, apoptosis \\
\hline
\end{tabular}

Tabla 1. Fármacos en los que la aparición de una lesión hepática se ha asociado a la dosis administrada. 
este cuadro es la resolución espontánea a los 3 meses de la suspensión del fármaco, aunque ocasionalmente puede cronificarse debido a la destrucción de los conductillos biliares, conocido como ductopenia o síndrome de la desaparición de conductos biliares ("vanishing bile duct síndrome"). Entre los fármacos que han sido involucrados con este tipo de lesión los más destacados son la amoxicilina-clavulánico, los antibióticos macrólidos y las fenotiazinas.

3. La lesión hepatocelular/colestásica mixta se asocia al aumento de ALT y FA mayor del doble del límite superior de la normalidad y una relación entre ALT/FA entre 2 y 5 . Las manifestaciones clínico-patológicas incluyen datos tanto de lesión hepatocelular como colestásica e incluye también en este grupo las lesiones granulomatosas. Se asocia frecuentemente a síntomas de hipersensibilidad y el pronóstico es generalmente bueno.

Dicha clasificación es aplicable únicamente a síndromes de toxicidad hepática aguda (menos de tres meses de evolución) y tiene una correspondencia aproximada con la lesión hepatocelular, colestasis canalicular y hepatocanalicular respectivamente.

\section{B. Lesión hepática crónica}

Las RAH se definen como crónicas cuando las anormalidades bioquímicas persisten más allá de tres meses. La persistencia del daño hepático puede ser debida a una exposición prolongada al producto responsable o bien a la secuela de un daño agudo. A pesar de que clásicamente los fármacos se han considerado responsables de menos de un $1 \%$ de los casos de afectación hepática crónica y cirrosis, estudios recientes demuestran que esta cifra es mayor. Las lesiones crónicas pueden ser necroinflamatorias (hepatitis crónica activa similar a la autoinmune), colestásicas, esteatósicas, por fosfolipidosis, fibrosis hepática y cirrosis, lesiones vasculares, granulomatosas o neoplásicas.

En la tabla 2 se exponen los distintos tipos de daño hepático según el tipo de célula afectada y los fármacos que con mayor frecuencia lo producen.

\section{MANIFESTACIONES CLÍNICO-PATOLÓGICAS}

Debido a la enorme variedad de síndromes producidos por las RAH, la expresión clínico-patológica de las lesiones es extraordinariamente variada, pudiendo causar desde alteraciones asintomáticas y reversibles de las enzimas hepáticas hasta necrosis hepática masiva e insuficiencia hepática fulminan- te ${ }^{14}$. La mayoría de las reacciones hepatotóxicas cursan de forma asintomática o con síntomas inespecíficos, por lo que se descubren habitualmente mediante la aparición de una elevación de los niveles de transaminasas (ALT y AST) o de las enzimas de colestasis (GGT y FA) en la analítica sanguínea. Los síntomas más frecuentes, cuando aparecen, son la astenia, la hiporexia, el malestar general, molestias a nivel del hipocondrio derecho y la ictericia. Otros síntomas y signos como la fiebre, el exantema cutáneo y la eosinofilia en sangre periférica son datos sugestivos de inmunoalergia que aparecen en un $20-25 \%$ e los casos de HTX ${ }^{8}$. El incremento bioquímico aislado de la enzima hepática gammaglutamil transpeptidasa es la reacción hepática a fármacos más frecuente y traduce un fenómeno de "inducción enzimática microsomal" sin repercusión patológica. Este hallazgo es especialmente común con la medicación antiepiléptica (difenilhidantoína y fenobarbital), pero muchos otros fármacos como la rifampicina y las benzodiazepinas pueden también causarla. En cambio, el aumento de transaminasas se produce por muerte de los hepatocitos y es una medida semicuantitativa sensible de lesión hepática.

Como se ha descrito previamente, el panel de expertos del Grupo Internacional de Consenso definió el daño hepático como la elevación de la ALT o bilirrubina total al doble del límite superior a la normalidad, o la elevación combinada de AST, FA o bilirrubina total, siempre que una de ellas supere el doble del límite superior a la normalidad ${ }^{2}$. Como regla general, niveles 3 veces mayores al límite superior de la normalidad son considerados como una señal sensible, aunque poco específica, de daño hepático significativo dado que dicho grado de elevación sólo se da en un $0.2-1 \%$ de los controles sanos. En cambio, un aumento bioquímico menor de dichas enzimas acompañado de niveles normales de bilirrubina indica la presencia de una alteración de carácter leve.

Hay ocasiones en las que la elevación de enzimas hepáticas no sólo no se acompaña de patología hepática significativa sino que puede disminuir o incluso normalizarse, a pesar de la continuación del tratamiento responsable del mismo, debido a la adaptación y tolerancia que desarrolla el tejido hepático ${ }^{27}$. Ejemplos característicos de lo previamente expuesto son la isoniazida y la tacrina. Tal y como indicó en 1978 Hy Zimmerman y se ha confirmado en estudios posteriores, la lesión hepatocelular asociada a ictericia presenta una mayor mortalidad, del 10 al $50 \%$ dependiendo del fármaco culpable de la lesión, por lo que la combinación de un aumento significativo del nivel de transaminasas por encima de 3 veces el límite superior de la normalidad, acompañado de ictericia con una bilirrubina mayor de 2-3 mg/dl o mayor de dos veces el límite supe- 


\begin{tabular}{|c|c|c|}
\hline Tipo de célula afectada & Cuadro clínico-patológico & Ejemplos \\
\hline \multirow{6}{*}{ Lesión hepatocitos } & Hepatitis Aguda Hepatocelular & \begin{tabular}{|l|} 
Paracetamol \\
Halotano \\
Isoniazida \\
Diclofenac \\
Sulfamidas \\
Trazodona \\
Nefazodona \\
Troglitazona
\end{tabular} \\
\hline & Hepatitis colestásica/mixta aguda & $\begin{array}{l}\text { Amoxicilina/Ac.clavulánico } \\
\text { Macrólidos (Eritromicina) } \\
\text { Clorpromacina }\end{array}$ \\
\hline & Hepatitis Granulomatosa & \begin{tabular}{|l|} 
Difenilhidantoína \\
Alopurinol \\
Sulfamidas \\
Diltiazem \\
\end{tabular} \\
\hline & Hepatitis Crónica & \begin{tabular}{|l} 
Nitrofurantoina \\
Diclofenac \\
Metildopa \\
Bentazepan \\
\end{tabular} \\
\hline & Esteatosis-Esteatohepatitis & \begin{tabular}{|l} 
Amiodarona \\
Tetraciclinas \\
Metotrexate \\
Acido Valproico \\
Inhibidores Transcriptasa inversa \\
Corticoides / Estrógenos \\
Tamoxifeno \\
Antagonistas del calcio \\
\end{tabular} \\
\hline & Adenoma/adenocarcinoma hepático & $\begin{array}{l}\text { Anticonceptivos orales } \\
\text { Andrógenos }\end{array}$ \\
\hline \multirow{3}{*}{ Colangiocito } & Colestasis aguda & \begin{tabular}{|l|} 
Anabolizantes \\
Estrógenos
\end{tabular} \\
\hline & Colestasis crónica & Clorpromacina \\
\hline & Colangitis esclerosante & \\
\hline \multirow{4}{*}{ Célula Endotelial } & Enfermedad venooclusiva & Azatioprina \\
\hline & Dilatación sinusoidal & Acido nicotínico \\
\hline & Peliosis hepática & Agentes quimioterápicos (ciclofosfamida) \\
\hline & Síndrome Budd-Chiari & Anticonceptivos orales/anabólicos \\
\hline Células estrelladas (Ito) & Fibrosis perisinusoidal & \begin{tabular}{|l} 
Metotrexate \\
Vitamina A
\end{tabular} \\
\hline
\end{tabular}

Tabla 2. Tipos de lesión hepática dependiendo del tipo de célula afectada y ejemplos de fármacos que la producen.

rior de la normalidad, es indicativo de una mayor riesgo de desarrollar una lesión hepática severa. Dicha regla es referida como la "Ley de Hy" ("Hy's rule") ${ }^{28}$. Esta regla ha sido incorporada por la FDA para la valoración del riesgo de hepatotoxicidad en los fármacos de nuevo desarrollo. En cuanto a la histología, aunque no existen patrones patognomónicos de HTX, ciertos patrones patológicos sugieren la etiología medicamentosa como son la necrosis centrolobulillar, la esteatosis microvesicular y las lesiones mixtas. Otros hallazgos que orientan hacia este diagnóstico son la presencia de lesiones necróticas desproporcionadamente severas en relación con el cuadro clínico del paciente, lesiones destructivas de los conductos biliares, la presencia de neutrófilos y eosinófilos y los granulomas.

\section{DIAGNÓSTICO DE HEPATOTOXICIDAD}

Es de vital importancia el diagnóstico correcto y temprano de las reacciones adversas hepáticas tanto para prevenir la evolución a formas más graves o su cronificación como para evitar la recurrencia del evento. Es más, un diagnóstico erróneo de HTX puede impedir o retrasar el diagnóstico etiológico correcto y por consiguiente también su tratamiento. Las principales razones que explican la dificultad diagnóstica en este tipo de patología son:

- Características clínicas inespecíficas.

- Ausencia de parámetros específicos. 
- Enfermedad hepática crónica previa.

- La enfermedad para la que se prescribe el fármaco sospechoso también puede producir alteraciones hepáticas.

- Toma de varios fármacos hepatotóxicos (ejemplo: combinación de fármacos antituberculosos $\mathrm{y}$ antirretrovirales).

- Compuestos que se consideran seguros como los productos de herboristería.

- Dificultad en el análisis de los medicamentos ingeridos por automedicación, compuestos ilegales, olvido o medicamentos comprados por la red.

- Hepatitis fulminante o subfulminante que no deja tiempo de evolución cronológica y no permite una valoración de los fármacos ingeridos.
La hepatotoxicidad no sólo es una enfermedad infradiagnosticada, debido en gran parte al bajo nivel de sospecha existente, sino también mal diagnosticada ya que un estudio reciente demostró que casi un $50 \%$ de los casos de reacciones adversas hepáticas remitidas a un comité de fármacovigilancia no estaban realmente relacionados con el fármaco incriminado, lo cual demuestra la subjetividad de dicha valoración ${ }^{29}$. Además, dado que los ensayos clínicos precomercialización no incluyen suficiente número de pacientes para la detección de fármacos con potencial hepatotóxico, el diagnóstico precoz y correcto de HTX puede hacer que el tiempo entre la introducción de un medicamento en el mercado y

\begin{tabular}{|c|c|c|}
\hline Fármaco & Monitorización recomendada & Actitud a adoptar \\
\hline Amiodarona & TFH basal y cada 6 meses & Si TFH $>3 \mathrm{~N}$ reducir dosis o suspender \\
\hline Carbamazepina & TFH basal y periódicamente & \\
\hline Felbamato & $\begin{array}{l}\text { TFH basal y cada } 1-2 \text { semanas mientras dure el } \\
\text { tratamiento }\end{array}$ & Suspender si TFH alterado \\
\hline Fenofibrato & TFH periódicos & Si TFH $>3 \mathrm{~N}$ suspender \\
\hline Isoniazida & $\begin{array}{l}\text { TFH basal y periódicos durante el tratamiento } \\
\text { periodicidad mensual o inferior) }\end{array}$ & $\begin{array}{l}\text { Si TFH }>3-5 \mathrm{~N} \text { o síntomas de hepatitis } \\
\text { suspender }\end{array}$ \\
\hline Isotretinoina & TFH basal y cada $1-2$ semanas & \\
\hline Itraconazol & $\begin{array}{l}\text { TFH en pacientes con alteraciones hepáticas y en } \\
\text { tratamientos que duren más de } 1 \text { mes }\end{array}$ & Si TFH $>3 \mathrm{~N}$ reducir dosis o suspender \\
\hline Ketoconazol & $\begin{array}{l}\text { TFH basal y periódicos durante el tratamiento } \\
\text { (periodicidad mensual o inferior) }\end{array}$ & $\begin{array}{l}\text { Suspender si alteraciones mínimas } \\
\text { persisten, empeoran o síntomas }\end{array}$ \\
\hline Leflunomida & $\begin{array}{l}\text { ALT basal y mensual los primeros } 6 \text { meses. Luego } \\
\text { cada } 1,5-2 \text { meses }\end{array}$ & $\begin{array}{l}\text { Si ALT }>2 \text { y }<3 N \text { reducir dosis. Si ALT }>3 N \\
\text { suspender y dar colestiramina }\end{array}$ \\
\hline Metotrexato & $\begin{array}{l}\text { TFH y albúmina sérica basal y cada } 1-2 \text { meses. } \\
\text { Biopsia hepática en pacientes seleccionados }\end{array}$ & $\begin{array}{l}\text { Si TFH > N persistentes y/o disminuye la } \\
\text { albúmina sérica debe estudiarse un daño } \\
\text { hepático }\end{array}$ \\
\hline Nefazodona & TFH basal y cada 3-6 meses & Si AST o ALT > 3N suspender \\
\hline Nevirapina & $\begin{array}{l}\text { TFH basal. Control intensivo las primeras } 18 \text { semanas } \\
\text { de tratamiento y luego frecuente }\end{array}$ & $\begin{array}{l}\text { Si AST o ALT > } 2 \mathrm{~N} \text { intensificar } \\
\text { monitorización. Si AST o ALT > } 5 \mathrm{~N} \\
\text { suspender }\end{array}$ \\
\hline Niacina & $\begin{array}{l}\text { AST y ALT basal cada } 6-12 \text { semanas el primer año y } \\
\text { luego cada } 6 \text { meses }\end{array}$ & $\mathrm{Si} \mathrm{TFH}>3 \mathrm{~N}$ o síntomas suspender \\
\hline AINE & $\begin{array}{l}\text { TFH basal y periódicamente (no establecido). ALT es el } \\
\text { indicador más sensible. }\end{array}$ & $\begin{array}{l}\text { Suspender si persisten o empeoran } \\
\text { TFH anómalos. }\end{array}$ \\
\hline $\begin{array}{l}\text { Pioglitazona } \\
\text { Rosiglitazona }\end{array}$ & $\begin{array}{l}\text { ALT basal y cada } 2 \text { meses el primer año, luego cada } \\
6 \text { meses }\end{array}$ & Si TFH $>3 \mathrm{~N}$ o ictericia suspender \\
\hline Pirazinamida & TFH basal y periódicamente (no establecido) & $\begin{array}{l}\text { Suspender si signos de } \\
\text { hepatotoxicidad }\end{array}$ \\
\hline Rifampicina & $\begin{array}{l}\text { TFH basal y cada } 2-4 \text { semanas (especialmente si el } \\
\text { paciente tiene una alteración hepática) }\end{array}$ & $\begin{array}{l}\text { Suspender si signos de } \\
\text { hepatotoxicidad }\end{array}$ \\
\hline Estatinas & $\begin{array}{l}\text { TFH basal y a las } 12 \text { semanas del inicio o del aumento } \\
\text { de dosis. Controles cada } 6 \text { meses. }\end{array}$ & $\begin{array}{l}\text { Si AST o ALT }>3 \mathrm{~N} \text { reducir dosis o } \\
\text { suspender tratamiento }\end{array}$ \\
\hline Valproato & $\begin{array}{l}\text { TFH basal y a intervalos frecuentes, especialmente los } \\
\text { primeros } 6 \text { meses }\end{array}$ & \\
\hline Voriconazol & TFH basal y periódicamente & $\begin{array}{l}\text { Suspender si signos o síntomas de } \\
\text { hepatotoxicidad }\end{array}$ \\
\hline
\end{tabular}

Tabla 3. Fármacos de amplio uso en los que es necesaria una monitorización estrecha de la función hepática. TFH = test de función hepática (incluye AST, ALT, fosfatasa alcalina, bilirrubina total); > 3N = valor 3 veces por encima del límite superior del rango de normalidad. 


\begin{tabular}{|c|c|}
\hline \multicolumn{2}{|c|}{$\begin{array}{l}\text { Métodos de imputación de causalidad de reacciones adversas a fármacos más } \\
\text { representativos }\end{array}$} \\
\hline Métodos inespecíficos & $\begin{array}{l}\text { Karch y Lasagna (1977) } \\
\text { Kramer (1979) } \\
\text { Naranjo (1981) } \\
\text { Jones (1982): Método de FDA. } \\
\text { Begaud (1984): Método francés. } \\
\text { Arimone (2006) }\end{array}$ \\
\hline Métodos específicos hepatotoxicidad & $\begin{array}{l}\text { Striker (1992) } \\
\text { CIOMS/RUCAM (1993) } \\
\text { Maria y Victorino (1997) }\end{array}$ \\
\hline
\end{tabular}

Tabla 4. Clasificación de los principales sistemas de atribución de causalidad.

su retirada se acorte, con la evidente reducción del riesgo de exposición para el resto de la población. Por lo tanto, es fundamental la sospecha clínica inicial de HTX ante cualquier cuadro de disfunción hepática, así como su posterior estudio y confirmación diagnóstica. La disponibilidad de marcadores moleculares de toxicidad hepática aplicables en la práctica clínica parece aún lejana. Es más, las técnicas de laboratorio disponibles hoy día para el diagnóstico de HTX son escasas y sólo son útiles en casos específicos y en su mayoría en el ámbito de la investigación como se describe a continuación:

- Demostración de niveles tóxicos del fármaco en sangre periférica. De utilidad en los casos de toxicidad intrínseca por sobredosificación como ocurre en los casos de intoxicación por paracetamol, ácido acetil-salicílico o vitamina $A$.

- Determinación de metabolitos del fármaco en hígado.

- Niveles periféricos de lgE total.

- La demostración de aductos de paracetamolproteína en suero presenta alta sensibilidad y especificidad para el diagnóstico de la hepatotoxicidad por paracetamol y podría ser en el futuro una técnica a aplicar no sólo en las intoxicaciones por sobredosis por dicho fármaco sino también en los casos de enfermedad hepática de causa desconocida.

- Demostración de la presencia de anticuerpos circulantes contra el fármaco, como los anticuerpos contra fracciones del citocromo-P450, sólo aplicable a un número limitado de compuestos, en su mayoría retirados del mercado y que se realiza únicamente en el ámbito de la investigación con escasa utilidad en la práctica clínica habitual (AMA M6-iproniacida, antiLKM2ácido tienílico, anti-CYP1A2-dihidralacina, anti CYP2E1-halotano, antimicrosomas hepáticoscarbamacepina y anti epóxido hidrolasa antimi- crosomal-germander).

El test de transformación linfocitaria in vitro se ha testado y usado en un intento de evidenciar casos de alergia farmacológica. Dicho método consiste en exponer las células mononucleares o linfocitos de sangre periférica del paciente al fármaco o sustancia sospechosa y la posterior determinación de la proliferación linfocitaria mediante timidina radio. Aunque una respuesta positiva ha sido considerada como una evidencia específica de que el fármaco es el responsable del daño hepático, tal respuesta puede reflejar únicamente una exposición previa al mismo, es decir, una sensibilización previa. $Y$ al contrario, un resultado negativo no excluye la presencia de alergia al compuesto. Además, dichas pruebas son difíciles de estandarizar, son poco reproducibles entre distintos laboratorios y no han alcanzado aceptación clínica por lo que es usado en pocos países ${ }^{30}$.

Debido a la ausencia de criterios clínicos o marcadores específicos en la mayoría de los casos, el diagnóstico constituye un verdadero desafío para los profesionales basado en el juicio clínico ${ }^{31}$. Esto implica que el establecimiento de causalidad se realice mediante un proceso secuencial "paso a paso", que requiere un alto índice de sospecha clínica y que está basado en la evidencia circunstancial de la exposición a un agente con potencial hepatotóxico, la exclusión de otras causas alternativas de daño hepático y la presencia de criterios "positivos" que apoyan el diagnóstico de HTX (figura 3).

\section{Evidencia de exposición a fármacos y evalua- ción del potencial hepatotóxico}

El primer paso para el diagnóstico de HTX, tras la sospecha clínica, es la realización de una anamnesis general y farmacológica minuciosa que tenga en cuenta todos los productos de prescripción o de li- 
bre dispensación consumidos en los meses previos, no olvidando los analgésicos como el paracetamol, los productos de herboristería, así como las drogas de abuso. No hay reglas claras para la imputación de un determinado fármaco en la aparición de un episodio de hepatotoxicidad cuando existen varios medicamentos sospechosos tomados de forma simultánea. En estos casos se debe prestar especial atención a los introducidos en los últimos 3 meses, fundamentalmente en el último prescrito o en el de mayor potencial hepatotóxico.

También es importante anotar la presencia de factores de riesgo y si han existido reacciones tóxicas a medicamentos en el pasado. Aunque prácticamente cualquier fármaco comercializado ha sido involucrado en algún caso de hepatotoxicidad, la capacidad de producir lesión hepática no es la misma para todos ${ }^{3}$. Por ejemplo, medicamentos como la digoxina, la teofilina y la estreptomicina se han venido utilizando durante décadas sin aparecer datos de HTX. Por el contrario, sustancias como la isoniazida, el diclofenaco y la amoxicilina-ácido clavulánico han sido los compuestos más frecuentemente implicados en enfermedad hepática secundaria a medicamentos en las últimas décadas. La información acerca de la probabilidad de causar lesión hepática es escasa o ambigua para la mayoría de los compuestos, así en la ficha técnica del producto son corrientes frases poco útiles como "pueden producir un incremento transitorio de las transaminasas" o "puede causar hepatitis en raras ocasiones".

Los medicamentos con potencial hepatotóxico pueden tener características específicas propias o "Firma" en cuanto a la temporalidad, tipo de lesión y las manifestaciones clínicas que producen, por lo tanto, aunque existe gran variabilidad interindividual, el conocimiento de estos datos es importante a la hora de la evaluación de casos de lesión hepática inducida por medicamentos. Por otro lado, también se debe tener en cuenta que existen excepciones a dicha regla, como ocurre por ejemplo con la troglitazona, cuya lesión más frecuente es de tipo hepatocelulcar, y sin embargo se han descrito casos de alteración colestásica. Otro ejemplo de este fenómeno es lo que ocurre con el antibiótico amoxicilina-ácido clavulánico cuyo patrón más característico es el colestásico, aunque también se han descrito casos de lesión hepatocelular e insuficiencia hepática aguda ${ }^{15}$. Esto demuestra lo abierta y alerta que debe estar la mente del profesional clínico a la hora de evaluar pacientes con sospecha de hepatotoxicidad.

\section{Secuencia temporal compatible}

Dentro de la historia farmacológica es importante hacer hincapié en la relación temporal entre la exposición al agente sospechoso, la aparición de la lesión hepática y la mejoría o desaparición de la misma tras su suspensión. En primer lugar y de forma obvia, se debe determinar si el tratamiento se instauró antes de la aparición del síndrome clínico. Este punto es en ocasiones difícil, dado que con frecuencia el cuadro comienza con síntomas generales inespecíficos no identificados, de hecho el agente sospechoso puede haber sido prescrito para el tratamiento de dichos síntomas iniciales.

El período de latencia entre el inicio del tratamiento y la aparición del síndrome hepático es variable, siendo más frecuente que ocurra entre una semana y tres meses tras la introducción del fármaco (5-90 días) en los casos de hepatotoxicidad idiosincrática y de horas tras la sobredosis de hepatotoxinas intrínsecas ${ }^{2}$. Un periodo mayor de 3 meses es menos habitual, pudiendo darse en el caso de fármacos que producen una hepatotoxicidad por acumulación gradual de metabolitos tóxicos. Si bien la hepatitis aguda tóxica rara vez ocurre tras más de 12 meses de exposición, sí puede darse en otras variedades de alteración hepática crónica como la esteatohepatitis, la hepatitis crónica y la fibrosis o en el caso de lesiones vasculares y tumorales ${ }^{32}$. A la inversa, un período de latencia muy corto (1 o 2 días) es compatible siempre que el paciente se haya "sensibilizado" por una exposición previa al compuesto en los casos de hepatotoxicidad inmunoalérgica. Por último, un hecho inusual, pero que desafía el proceso de imputación de un fármaco, es la aparición del síndrome hepático varias semanas tras la interrupción de un curso terapéutico como puede ocurrir con el antibiótico amoxicilina/ácido clavulánico, el trovafloxacino o la midecamicina ${ }^{15}$.

\section{Exclusión de causas alternativas de lesión he- pática}

La carencia de especificidad clínica y de laboratorio de las reacciones hepatotóxicas obliga a excluir otras causas de daño hepático. Dicha evaluación debe incluir la exclusión de ingesta alcohólica, la realización de pruebas serológicas de los virus hepatotropos A, B y C, el citomegalovirus y el virus de Epstein-Barr (IgM anti-VHA, IgM anti-HBc, anti-VHC, PCR VHC, IgM CMV y EBV), serología bacteriana (Salmonella, Campylobacter, Listeria, Coxiella) en los casos en los que haya síntomas de infección bacteriana, la determinación de marcadores de autoinmunidad (anticuerpos antinucleares, anticuerpos anti mitocondriales, anticuerpos anti-músculo liso y anticuerpos antimicrosomas del hígado y riñón de tipo I o Anti-LKM1) y marcadores metabólicos (ceruloplasmina, índice de saturación de transferrina, alfa-1-antitripsina) ${ }^{2,6}$. Conviene señalar que la presencia de autoanticuerpos, y especialmente ante títulos altos de anti-músculo liso, no 
descarta el diagnóstico de hepatotoxicidad dado que existen reacciones que se acompañan de alteraciones serológicas de autoinmunidad. En estos casos estaría indicada la realización de una biopsia hepática para realizar el diagnóstico diferencial entre ambas entidades. También conviene señalar si han existido episodios de hipotensión o sepsis previo al comienzo del evento, lo que podría indicar el desarrollo de hepatitis isquémica o un fallo multiorgánico respectivamente.

Por último, las pruebas de imagen como la ultrasonografía, la colangioresonancia magnética, el TAC de abdomen y la colangiopancreatografía retrógrada endoscópica ayudan a descartar lesiones neoplásicas, vasculares y patología de la vía biliar. De ellas, la más utilizada es la ecografía abdominal por su menor coste y riesgo.

La realización de exploraciones o estudios adicionales dependerá del ámbito clínico y de la presencia de síntomas particulares, por ejemplo, la realización de serología de sífilis cuando existe un aumento desproporcionado de fosfatasa alcalina o en pacientes con antecedentes de prácticas de riesgo.

\section{Criterios positivos}

Una vez excluidas las causas alternativas de enfermedad hepática, la probabilidad diagnóstica de HTX puede reforzarse analizando la presencia de manifestaciones de hipersensibilidad y otros criterios clínicos positivos, evaluando la evolución del cuadro tras la suspensión del agente causal, la presencia de reexposición positiva, el hallazgo de lesiones anatomopatológicos compatibles y la identificación de la firma farmacológica particular en el patrón biológico de lesión. La presencia de manifestaciones extrahepáticas como lesiones cutáneas (exantema, Síndrome de Lyell o Síndrome de Stevens-Johnson), fiebre, manifestaciones hematológicas (eosinofilia, granulocitopenia, trombopenia o anemia hemolítica) y afectación de otros órganos (riñón y páncreas) son fuertemente sugestivas de hipersensibilidad a fármacos. Sin embargo, dado que estos signos ocurren en una minoría de casos (23 \% de los casos del Registro Español de Hepatotoxicidad), su sensibilidad es muy baja.

La evolución del cuadro tras la supresión del agente sospechoso ("dechallenge") puede contribuir, de igual modo, al establecimiento de la causalidad. La rápida mejoría clínica y del perfil hepático es la regla al interrumpir el fármaco responsable. Si el patrón de lesión es hepatocelular, un descenso de al menos un $50 \%$ en los niveles séricos de ALT o AST durante los primeros 30 días (particularmente si ocurre durante la primera semana) tras la sus- pensión constituye una evidencia de peso a favor del fármaco ${ }^{2}$. La colestasis tóxica, por su parte, tiene una resolución habitualmente más lenta que la hepatocelular, pudiendo persistir alteraciones analíticas hasta un año tras la retirada del medicamento. Notables excepciones que impiden evaluar el efecto de la retirada son la progresión del episodio de hepatitis aguda a una insuficiencia hepática fulminante, el transplante hepático, el exitus o los casos que evolucionan a la cronicidad. A la inversa, un fenómeno de "adaptación" cuya consecuencia es la mejoría a pesar de la continuación del tratamiento es frecuente con algunos agentes como las estatinas $^{32}$.

La reexposición positiva ("rechallenge") al agente sospechoso con la consiguiente recidiva del daño hepático es considerado como el "gold standard" en la evaluación de HTX. Se considera diagnóstico un incremento del doble de los valores de ALT y FA tras la reexposición para la lesión hepatocelular 0 colestásica respectivamente. La recidiva clínica del cuadro es especialmente probable cuando el episodio índice se asoció con manifestaciones de hipersensibilidad. A la inversa, para casos de RAH por mecanismo metabólico un corto período de exposición (unas pocas dosis) puede ser insuficiente para generar una concentración crítica de metabolitos tóxicos, dando lugar a "falsos negativos". Es más, la dosis y duración necesarias para provocar la recidiva del cuadro son desconocidas. Por esto y por razones éticas obvias, resulta inaceptable realizar la readministración de un fármaco sospechoso de producir HTX de forma no accidental debido al riesgo de precipitar un cuadro hepático grave. La única indicación de su realización sería en los casos de imputación poco probable en los que no haya medicamentos alternativos para el tratamiento de enfermedades graves. No obstante, frecuentemente puede haber una historia de exposición previa que requiere cierta pericia para reconocerla. En tales casos el primer episodio, tras la administración del fármaco, pudo manifestarse de forma inespecífica sin acompañarse de ictericia pasando de forma inadvertida.

Las lesiones debidas a fármacos pueden simular cualquier enfermedad hepática conocida. Este hecho hace que la biopsia hepática rara vez proporcione el diagnóstico definitivo y por lo tanto no es imprescindible para la evaluación de causalidad en $\mathrm{HTX}^{33}$. Las indicaciones para su realización están restringidas a los casos en los que la etiología tóxica es menos probable y deban excluirse otras causas alternativas, cuando el fármaco sospechoso no haya sido previamente imputado en reacciones hepatotóxicas con el fin de caracterizar el patrón de lesión que produce y con fines pronósticos (por ejemplo evaluar la fibrosis residual o la presencia de ductopenia) $)^{6}$. Aunque los resultados anatomo- 
patológicos no son patognomónicos, los hallazgos histológicos que sugieren hepatotoxicidad son los siguientes: necrosis de predominio centrolobulillar (área de mayor actividad del CYP), esteatosis microvesicular particularmente si es zonal y asociada a necrosis, lesiones mixtas (necrosis y colestasis), infiltrado inflamatorio rico en eosinófilos, granulomas, lesiones destructivas de los ductos biliares y colestasis periportal y lesiones vasculares. La presencia de lesiones necróticas desproporcionadamente severas en relación con el cuadro clínico asociado también orientan hacia la posibilidad de una causa medicamentosa ${ }^{1}$. En los casos de intoxicación por vitamina A se puede apreciar el depósito de una sustancia con autofluorescencia verdosa característica bajo la luz ultravioleta. Por último, la cianamida se ha asociado con la aparición de cuerpos de inclusión similares a los hallados en el síndrome de LaFora en el tejido hepático.

\section{ESTRATEGIAS DE MONITORIZACIÓN Y CON- TROL DE LA FUNCIÓN HEPÁTICA}

Existen algunos fármacos en los que es conocido que existe un riesgo de lesión hepática relativamente frecuente, o bien que este riesgo puede asociarse a gravedad, en los que se han definido estrategias de monitorización y control de la función hepática para tratar de evitar el desarrollo de lesiones graves. En la tabla 3 se puede observar los controles a realizar recomendados y la actitud a tomar según el resultado obtenido.

\section{METODOS DE EVALUACIÓN DE CAUSALIDAD}

El factor crítico en el diagnóstico de una reacción adversa es el establecimiento de una relación causal entre el fármaco sospechoso y el evento clínico analizado. La valoración de causalidad de los efectos adversos basada en la impresión diagnóstica del clínico presenta variaciones y diferencias de opinión considerables, lo cual deriva en una baja reproducibilidad y validez en los resultados. Para obviar este problema y en un intento de asignar un valor cuantitativo uniforme a la imputabilidad de un agente en una reacción, en las últimas décadas se han desarrollado más de 20 métodos para la evaluación de causalidad de los efectos adversos secundarios a fármacos ${ }^{34}$. Estos métodos se pueden dividir en tres categorías: el juicio clínico de expertos en la materia, métodos diagnósticos y los sistemas de aproximación probabilística (basada en el teorema de Bayes). La imputación de causalidad basada en el juicio clínico de expertos en la materia no es un método estandarizado y por lo tanto presenta problemas de subjetividad similares al diagnóstico clínico. Es más, en diferentes estudios el acuerdo alcanzado entre expertos en la valoración de casos de reacciones adversas no llegaba al $50 \%{ }^{35}$. A pesar de sus limitaciones, hoy en día la mayor parte de las valoraciones de efectos adversos se realiza mediante la aplicación del juicio clínico individual ${ }^{36}$. Es más, parece que la valoración de expertos mediante el método de introspección global de la OMS está ganando adeptos en los últimos años.

En las últimas décadas se han desarrollado múltiples sistemas de imputación de causalidad compuestos por algoritmos, tablas de decisión y escalas diagnósticas, que pretenden posibilitar resultados más válidos y reproducibles, independientemente del entrenamiento y la calidad de conocimientos que posea la persona encargada de su interpretación ${ }^{37}$. Además, estos sistemas también ofrecen una guía para la valoración sistemática de los casos en los que se sospecha la aparición de una reacción adversa. Los requisitos que deben tener los sistemas de imputación de causalidad son validez y reproducibilidad. Además de disminuir el desacuerdo entre distintos asesores o intraobservador, deben clasificar la relación de probabilidad en categorías semicuantitativas amplias y deben permitir la valoración de notificaciones individuales. Estos sistemas se pueden clasificar a su vez en generales o no órgano-específicos y órgano específicos (tabla 4).

Los criterios que atribuyen causalidad son comunes para la mayoría de estos métodos: la relación cronológica, la exclusión de causas alternativas, la confirmación de la relación mediante la realización de un test in vitro o in vivo y la presencia de información previa sobre eventos similares atribuidos al medicamento o a otros fármacos del mismo grupo terapéutico. La mayoría de las escalas diagnósticas consisten en un sistema de puntuación en el que cada parámetro valorado recibe un valor cuantitativo de acuerdo a su presumible importancia para el diagnóstico de la reacción y cuya suma corresponde a distintos niveles de certeza.

\section{BIBLIOGRAFÍA}

1. Farrel GC. Hepatopatía causada por fármacos, anestésicos y toxinas. En: Sleisenger y Fordtran eds. Enfermedades gastrointestinales y hepáticas: Fisiopatología diagnóstico y tratamiento. $7^{\mathrm{a}}$ ed. Buenos Aires: Ed. Panamericana; 2004. p. 1486-1537.

2. Benichou C. Criteria of drug-induced liver disorders. Report of an international consensus meeting. J Hepatol. 1990; 11:272-6.

3. Biour M, Poupon R, Grange JD, Chazouilleres O. Drug-induced hepatotoxicity. The 13th updated edition of the bibliographic database of drug-related liver injuries and responsible drugs. Gastroenterol Clin Biol. 2000; 24:1052-91.

4. Davis M, Williams R. Hepatic disorders. In: Davies DM, ed. Textbook of Adverse Drug Reactions. Oxford: Oxford University Press; 1977. p. 146-172.

5. Temple RJ, Himmel MH. Safety of newly approved drugs: 
implications for prescribing. JAMA. 2002 1; 287:2273-5.

6. Larrey D. Drug-induced liver diseases. J Hepatol 2000; 32:77-88.

7. Sgro C, Clinard F, Ouazir K, Chanay H, Allard C, Gilleminet $\mathrm{C}$, et al. Incidence of drug-induced hepatic injuries: a French population-based study. Hepatology. 2002; 36:451-5.

8. Ibáñez L, Pérez E, Vidal X, Laporte JR, Grup d'Estudi Multicenteric d'Hepatotoxicitat Aguda de Barcelona (GEMHAB). Prospective surveillance of acute serious liver disease unrelated to infectious, obstructive, or metabolic diseases: epidemiological and clinical features, and exposure to drugs. J Hepatol. 2002; 37:592-600.

9. De Abajo FJ, Montero D, Madurga M, García Rodríguez LA. Acute and clinically relevant drug-induced liver injury: a population based case-control study. Br J Clin Pharmacol. 2004; 58:71-80.

10. Dossing M, Sunne J. Drug induced hepatic disorders. Incidence, management and avoidance. Drug Saf. 1993; 9:441-9.

11. Ostapowicz G, Fontana RJ, Schiodt FV, Larson A, Davern $\mathrm{TJ}$, Han $\mathrm{SH}$, et al. Results of a prospective study of acute liver failure at 17 tertiary care centers in the United States. Ann Intern Med 2002; 137:947-54.

12. Williams R. Classification, etiology, and considerations of outcome in acute liver failure. Semin Liver Dis. 1996; 16:343-8.

13. Ostapowicz G, Lee WM. Acute hepatic failure: a Western perspective. J Gastroenterol Hepatol. 2000; 15:480-8.

14. Pessayre D, Larrey D, Biour M. Drug-induced liver injury. In: Bircher J, Benhamou JP, McIntyre N, Rizzeto M, Rodes J, editors. Oxford textbook of Clinical Hepatology, 2nd ed. Oxford: Oxford University Press; 1999. p. 1261- 315.

15. Lucena MI, Andrade RJ, Fernández MC, Pachkoria K, Peláez G, Duran JA, et al. Determinants of the clinical expression of amoxicillin-clavulanate hepatotoxicity: A prospective series from Spain. Hepatology. 2006; 44:850-6.

16. Zimmerman HJ. The adverse effects of drugs and other chemicals on the liver. 2nd ed. Philadelphia: Lippincott Williams \& Wilkins; 1999.

17. Lee WM. Drug-induced hepatotoxicity. N Engl J Med. 1995; 333:1118-27.

18. Pessayre D. Role of reactive metabolites in drug-induced hepatitis. J Hepatol. 1995; 23 Suppl 1:16-24.

19. Larrey D, Pageaux GP. Genetic predisposition to drug-induced hepatotoxicity. J Hepatol. 1997; 26:12-21.

20. Hoft RH, Bunker JP, Goodman HI, Gregory PB. Halothane hepatitis in three pairs of closely related women. $\mathrm{N}$ Engl J Med. 1981; 304:1023-4.

21. Krahenbuhl S, Brandner S, Kleinle S, Liechti S, Straumann D. Mitochondrial diseases represent a risk factor for valproate-induced fulminant liver failure. Liver. 2000; 20:346-
8.

22. Mehra R, Murren J, Chung G, Smith B, Psyrri A. Severe irinotecan-induced toxicities in a patient with uridine diphosphate glucuronosyltransferase 1A1 polymorphism. Clin Colorectal Cancer. 2005; 5:61-4.

23. Belay ED, Bresee JS, Holman RC, Khan AS, Shahriari A, Schonberger LB. Reye's syndrome in the United States from 1981 through 1997. N Engl J Med. 1999; 340:137782.

24. Russo MW, Galanko JA, Shrestha R, Fried MW, Watkins P. Liver transplantation for acute liver failure from drug induced liver injury in the United States. Liver Transpl. 2004; 10:1018-23.

25. Teoh NC, Farrell GC. Hepatotoxicity associated with nonsteroidal anti-inflammatory drugs. Clin Liver Dis. 2003; 7:401-13.

26. Lee WM. Drug-induced hepatotoxicity. N Engl J Med. 2003; 349:474-85.

27. Watkins PB. Idiosyncratic liver injury: challenges and approaches. Toxicol Pathol. 2005; 33:1-5.

28. Bjornsson E. Drug-induced liver injury: Hy's rule revisited. Clin Pharmacol Ther 2006; 79:521-8.

29. Meier Y, Cavallaro M, Roos M, Pauli-Magnus C, Folkers G, Meier PJ, et al. Incidence of drug-induced liver injury in medical inpatients. Eur J Clin Pharmacol 2005; 61:135-43.

30. Maria VA, Victorino RM. Immunological investigation in hepatic drug reactions. Clin Exp Allergy. 1998; 28:71-7.

31. Nierenberg DW. "Did this drug cause my patient's hepatitis?" and related questions. Ann Intern Med. 2002; 136:4803.

32. Kaplowitz N. Drug-induced liver disorders: implications for drug development and regulation. Drug Saf. 2001; 24:48390.

33. Bianchi L. Liver biopsy in elevated liver functions tests? An old question revisited. J Hepatol. 2001; 35:290-4.

34. Arimone $Y$, Begaud B, Miremont-Salame G, Fourrier-Reglat A, Molimard M, Moore N, et al. A new method for assessing drug causation provided agreement with experts' judgment. J Clin Epidemiol. 2006; 59:308-14.

35. Arimone $Y$, Begaud B, Miremont-Salame G, Fourrier-Reglat A, Moore N, Molimard M, et al. Agreement of expert judgment in causality assessment of adverse drug reactions. Eur J Clin Pharmacol. 2005; 61:169-73.

36. Clark JA, Klincewicz SL, Stang PE. Spontaneous adverse event signalling methods: classification and use with health care treatment products. Epidemiol Rev. 2001; 23:191210.

37. Stephens MDB. The detection of new adverse Drug reactions. 2nd ed. London: MacMillan; 1988. 